\title{
Espaço e Cicloturismo: a representação urbano-turística de Curitiba/PR em fotografias postadas no Tripadvisor
}

Space and Ciclotourism: the urban-touristic representation of Curitiba/PR in photographs posted at Tripadvisor

Renata C. Klos (renatacklos@gmail.com)

Doutoranda em Geografia, Universidade Federal do Paraná, Curitiba - Paraná

Marcelle Miskalo-Cruz (miskalo@gmail.com)

Mestranda em Turismo, Universidade Federal do Paraná, Curitiba - Paraná

Lauro Moraes (lauromoraes@ufpr.br)

Doutorando em Geografia, Universidade Federal do Paraná, Curitiba - Paraná

\section{RESUMO}

A gestão do espaço urbano-turístico é um dos componentes elementares para a competitividade de destinos, ainda mais frente ao desenvolvimento tecnológico e a cibercultura, que permitiram a incorporação de novos conceitos ao planejamento urbano e ao turismo, como a ideia de mobilidade inteligente (smart mobility). Deste modo, o presente trabalho propõe analisar a representação urbano-turística de Curitiba em fotografias compartilhadas por cicloturistas no site TripAdvisor. Realizou-se uma investigação exploratória por meio de pesquisa bibliográfica, documental e da netnografia, que permitiram a análise de 162 imagens, caracterizando-as por variáveis advindas da morfologia, da paisagem, da imagem do espaço urbano e das representações urbano-turísticas organizadas por Manosso (2015) a partir de Lynch (1997), Boullón (2002), Lamas (2004) e Cullen (1983). Observou-se que o cicloturista fotografou, em sua maioria, representações de cunho históricocultural, seguido de aspectos naturais e urbanos.

Palavras-chave: cicloturismo, representação urbano-turística, fotografia, smart mobility. 
The management of urban-tourist space is one of the elementary components for the competitiveness of destinations, even more in face of technological development and cyberculture, which allowed the incorporation of new concepts in urban planning and tourism, such as the idea of intelligent mobility (Smart Mobility). In this way, the present work proposes to analyze the urbantourist representation of Curitiba in photographs shared by cyclotourists in the TripAdvisor site. An exploratory investigation was carried out through bibliographical, documental and netnography research, which allowed the analysis of 162 images, characterizing them by variables derived from morphology, landscape, image of urban space and urban-tourist representations organized by Manosso (2015) from Lynch (1997), Boullón (2002), Lamas (2004) and Cullen (1983). It was observed that the cyclotourist photographed, for the most part, historical-cultural representations, followed by natural and urban aspects.

Keywords: tourism cycling, urban-tourist representation, photography, smart mobility.

\section{INTRODUÇÃO}

No intento tornar os destinos mais competitivos, as alterações no espaço urbano-turístico buscam a inovação e, muitas vezes, propiciam novas experiências e um novo olhar para a cidade. Estes conceitos e pensamentos trazem consigo a inovação e consequentemente, a utilização destas transformações para o bem comum (Custódio, 2006). Dentre estas mudanças, há destaque para o uso das ciclovias como um fator da mobilidade urbana sustentável nas cidades, que proporcionam acesso ao espaço urbano de maneira socialmente inclusiva e ecologicamente sustentável (Curitiba, 2015).

A cidade de Curitiba, desde 1940, quando possuía aproximadamente 127 mil habitantes, preocupava-se com a organização de seu espaço. Nesta época, a Prefeitura Municipal de Curitiba, com o intuito de disciplinar a ocupação do solo, elaborou um plano urbanístico para a cidade. Atualmente citada como "capital de primeiro mundo", "capital brasileira da qualidade de vida" ou, ainda, "capital ecológica do Brasil", Curitiba é internacionalmente reconhecida, através de prêmios internacionais, por sua eficiência 
administrativa, gestão e planejamento urbano inovadores, o que desperta a curiosidade de muitos visitantes e turistas (Curitiba, 2015).

Atenta ao movimento crescente da utilização da bicicleta como meio de locomoção sustentável tanto de residentes quanto turistas, a Prefeitura de Curitiba tem desenvolvido e implantado diversos projetos de incentivo ao uso da bicicleta na cidade. Ao perceber as imagens postadas pelos turistas sobre suas percepções do espaço urbano-turístico da cidade, tem-se a possibilidade de refletir sobre a gestão destes locais. Deste modo, este trabalho tem por objetivo analisar a representação urbano-turística do destino Curitiba/PR por meio de fotografias postadas por cicloturistas no site TripAdvisor, captando nuanças do olhar deste turista sobre a cidade.

\section{ESPAÇO URBANO E TURISMO}

Como consequência das rápidas mudanças socioculturais, econômicas e ambientais, as cidades passam por uma adequação voltada aos meios de gestão que sejam condizentes com a realidade observada e promovida pelas transformações tecnológicas com rápido incremento dos processos de desenvolvimento e de seus espaços.

A rápida urbanização exige dos órgãos governamentais uma responsabilidade ainda maior na implantação de programas de desenvolvimento propiciando melhores condições e maior organização do espaço da cidade (Custódio, 2006).

Esses espaços possuem características diferentes e são representados de maneiras distintas por aqueles que o utilizam. As representações e a materialização delas são registros de momentos vivenciados que retratam a imagem que cada pessoa visitante terá da cidade (Frey, 2000).

Os espaços urbanos acabam por estimular sensações diferenciadas, em que cada indivíduo extrai para si visões diferentes sobre a mesma cidade. Os aspectos arquitetônicos e o traçado da sua construção, a adaptação da geografia existente aliada à infraestrutura básica influencia a realização e o estabelecimento de movimentos que cativam tanto a população quanto ao visitante. Do mesmo modo, o planejamento gerado ao visitante deve ser 
aproveitado pelo cidadão local, pois, se as suas condições não forem adequadas, a receptividade poderá ser comprometida (Comissão Europeia, 2000, p. 9).

Para Lynch (1997) a cidade é considerada uma construção no espaço sendo percebida ao decorrer de longos períodos. Castrogiovanni (2000) reforça a dinamicidade das cidades ao salientar que contemplá-las e observá-las têm suas peculiaridades, pois quanto mais comum o cenário urbano aparenta ser, mais diferenças tornam-se evidentes dentro deste.

Os visitantes de uma cidade podem ter uma leitura muito tênue daquilo que em determinado espaço urbano pode significar em termos de prazer cotidiano para os moradores fixos. Nem sempre ao turista é permitida a total inserção com o território que visita, e, em certas circunstâncias, talvez nem devesse ocorrer. As imagens ambientais são resultado de um processo bilateral entre o observador e seu ambiente. Este último sugere especificidades e relações, e o observador seleciona - com grande capacidade de adaptação e à luz de seus próprios objetivos organiza e confere significado àquilo que vê (Lynch, 1997, p. 7).

Assim, a imagem de um determinado lugar pode variar dependendo de cada observador. No caso do turista no espaço urbano o tempo todo que estiver transitando estará realizando suas observações (Custódio, 2006).

Lefebvre (2008) destaca que o espaço pode ser considerado o produto resultante das relações de produção que se encontram a cargo de um grupo atuante e que, como tal, se torna objeto de troca. Santos (1988) e Lefebvre (1999) salientam, ainda, que a cidade é a forma, a materialização de determinadas relações sociais, enquanto o espaço urbano é o conteúdo, a materialização no espaço das próprias relações sociais.

Segundo Tyler, Guerrier \& Robertson (2001), o turismo urbano envolve os processos sociais de mudança e os processos de decisões políticas que ditam a natureza dessa mudança e que identificam ganhadores e perdedores. Trata-se da busca dos meios pelos quais a mudança afeta os processos sociais 
da cidade e da necessidade de gerenciar a inevitabilidade do turismo urbano.

A ordenação urbana compreende o processo de organização dos elementos que compõem o espaço urbano de acordo com o estabelecimento de relações de ordem, com base na construção de uma hierarquia de valores, no caso, com o objetivo de facilitar o desenvolvimento das atividades turísticas. A ordenação turística é a busca conveniente dos meios existentes no espaço para o sucesso das propostas relativas às atividades turísticas (Castrogiovanni, 2000, p. 23).

Lefebvre (2008) aponta que a cidade, ao ser comparada a uma obra de arte, demonstra que seu espaço não é apenas organizado e instituído, pois nas cidades o espaço é apropriado por determinados grupos conforme suas exigências estéticas e éticas. Leite (2009) complementa que com os pontos relacionados aos distintos papéis que a cidade possui, torna a mesma singular, por ser um ambiente artificial e construído pelo homem guardando, assim, as especificidades que a caracterizam e a identificam no contexto urbano.

Para Boullón (2002) o espaço turístico é consequência da presença e distribuição territorial dos atrativos turísticos que são a matéria-prima do turismo. Este elemento do patrimônio turístico, mais o empreendimento e a infraestrutura turística, são suficientes para definir o espaço turístico de qualquer país.

Os elementos urbanos que podem ser analisados pelos turistas segundo Boullón (2002) são seis: 1) pontos de interseção: áreas abertas ou cobertas de uso público onde o turista as percorre livremente. Por exemplo: praças, parques, mercado, igrejas shoppings ou galerias; 2) marcos divisórios: construções, artefatos urbanos e monumentos que se destacam na paisagem urbana como pontos de referência exterior ao observador; 3) bairros: áreas da cidade que tiveram a sua ocupação planejada ou podem ter passado por processo de urbanização após a sua ocupação inicial; 4) setores: áreas específicas dos bairros apresentando-se como rugosidades dentro da homogeneidade que tendem a ser os bairros. Por exemplo: setores históricos; 5) bordas ou franjas urbanas: elementos lineares que marcam o limite ou 
transição da passagem entre áreas ou do próprio todo que se constitui o tecido urbano. São elementos fronteiriços que tendem a ser uma terceira paisagem, trazendo características das duas paisagens que se encontram; 6) caminhos: são as ruas, avenidas, becos e passagens que podem ser considerados as melhores opções para se visitar os atrativos turísticos ou entrar na cidade e sair dela. O caminho pode passar a ser o principal atrativo.

Lamas (2004) discorre a respeito dos conceitos a partir dos elementos morfológicos do espaço urbano, que segundo ele são: ruas e traçados, escala bairro, monumentos, fachadas, praças, jardins, áreas verdes, e mobiliário urbano. Portanto, de acordo com o autor, o estudo da morfologia urbana "(...) ocupa-se da divisão do meio urbano em partes (elementos morfológicos) e da articulação destes entre si e com o conjunto que definem os lugares que constituem o espaço urbano" (Lamas, 2004, p. 38).

Cullen (1983), em sua obra 'Paisagem Urbana' analisa o espaço urbano com uma nova perspectiva por meio do emprego da apreciação das particularidades presentes na paisagem. Desse modo, Lopes (2010) ressalta que, de acordo com Cullen (1983), a cidade deve ser projetada com o intuito de criar emoções ao cidadão, pois este deve viver a cidade, aprender o espaço a partir da ótica, do local e do conteúdo, sendo que o combate à monotonia é realizado por meio de jogos de elementos, contrastes, cores, texturas, escalas em conjunção com um todo emotivo dentro do contexto da cidade. Cullen (1983), em seu estudo busca, então, englobar os seguintes aspectos do espaço urbano: as estradas, as barreiras e restrições, os recintos e os pontos focais.

A Tabela 1, organizada por Manosso (2015), explicita as representações urbano-turísticas e as categorias de análise referentes ao espaço urbano e as perspectivas que Lynch (1982), Boullón (2002), Lamas (2004) e Cullen (1983) apresentam em suas obras.

Tabela 1 - Categorias de análise do espaço urbano-turístico 


\begin{tabular}{|c|c|}
\hline \multirow{5}{*}{ Urbana } & $\begin{array}{l}\text { Vias (Caminhos) = Estradas, ruas, traçados, } \\
\text { calçadas. }\end{array}$ \\
\hline & Bairros = Escala bairro, bairros, setores. \\
\hline & Limites = Barreiras, restrições, bordas. \\
\hline & Sinalização urbana e turística. \\
\hline & Mobiliário urbano. \\
\hline \multirow{4}{*}{ Natureza } & Parques. \\
\hline & Passeios públicos e jardins. \\
\hline & Praças. \\
\hline & Ruas arborizadas. \\
\hline \multirow{6}{*}{ Histórico-Cultural } & Marcos. \\
\hline & Pontos nodais e pontos focais. \\
\hline & Logradouros. \\
\hline & Recintos. \\
\hline & Monumentos. \\
\hline & Fachadas. \\
\hline \multirow{4}{*}{ Entretenimento } & Lazer e recreação. \\
\hline & Compras. \\
\hline & Gastronomia. \\
\hline & Roteiros urbano-turísticos. \\
\hline
\end{tabular}

FONTE: Manosso (2015) com base em Lynch (1982); Boullón (2002); Lamas (2004) e Cullen (1983).

O espaço urbano não é construído para uma pessoa, mas para várias, que apresentam diferenças de temperamento, formação, ocupação profissional, origem étnica, diversidade social e, portanto, interesses. Assim, a cidade é uma representação da condição humana, sendo que essa representação se manifesta por meio da arquitetura em si e da ordenação de seus elementos (Castrogiovanni, 2000).

Os espaços que são vivenciados tanto por seus moradores quanto pelos turistas que a visitam, tornam-se espaços ricos pelas experiências, pelas vivências e pelas expectativas. Logo, a cidade é o resultado de uma relação intima entre o lugar e o espaço, um palco de transformações e interações de apropriação e de memória (Bettencourt, 2010). 
Uma maneira utilizada por órgãos públicos em todos os níveis para melhorar a vida das pessoas que estão na cidade é aderir a noção de inteligência (associada diretamente à obtenção de sucesso) às suas políticas, estratégias e programas para alcançar o desenvolvimento sustentável, o crescimento econômico sólido e a melhoria da qualidade de vida dos seus cidadãos (Center on Governance, 2003).

Deste ponto surgem as cidades inteligentes ou as chamadas smart cities. Estas têm proporcionado experiências diferenciadas a seus visitantes e moradores por meio da infraestrutura e soluções sustentáveis auxiliadas pela tecnologia da informação e comunicação, contribuindo para a melhoria da qualidade de vida e um crescimento econômico sustentável, através de um modelo de gestão governamental participativo (Caragliu, Del Bo \& Nijkamp, 2009), representando a base para a competitividade do destino (Xiang, Tussyadiah \& Buhalis, 2015) e onde a acessibilidade, inovação, sustentabilidade e tecnologia são seus maiores pilares (Associacion Española de Normalizacion y Certificacion -AENOR, 2016).

Entretanto, por não existir padronização graças ao seu caráter adaptativo e flexível, localidades e destinos podem se autodenominar smart sem o efetivo estudo local e a aplicação de indicadores que possam atestar tal condição, sendo a utilização deste termo, nesta condição, se enquadrar em uso inapropriado, puramente retórico e propagandístico (Vera Rebollo \& Ivars Baidal, 2004).

Como as cidades inteligentes, os Destinos Turísticos Inteligentes tornaramse referência de inquestionável atualidade. Este enfoque irrompeu com força na gestão urbana e adentrou à gestão turística (Ivars Baidal, Solsona Monzonís \& Giner Sánchez, 2016), sendo possível dizer que os Destinos Turísticos Inteligentes supõem a evolução natural das smart cities (Luque Gil, Zayas Fernández \& Caro Herrero, 2015). 
O Destino Inteligente é impulsionado pelo setor do turismo, tanto público quanto privado; o público-alvo é o turista e não o cidadão; a oferta consiste em experiências de turismo que são vividas em um destino; os Destinos Turísticos Inteligentes estão ligados ao aumento da competitividade da indústria e para a experiência turística melhorar; a interação vai muito além do tempo gasto na cidade (Ávila Muñoz, 2013, p. 18).

Portanto, certo é que o turismo possui característica importante no processo de desenvolvimento de uma localidade, pois, para melhor atender os visitantes, ocorre uma significativa melhora na infraestrutura local, não somente na turística, como equipamentos e serviços, mas também na urbana, como, infraestruturas de base, de acesso, enfim, desenvolve a região sob todos os aspectos (Rodrigues, 2002).

\section{MOBILIDADE INTELIGENTE E CICLOTURISMO NA CIDADE DE CURITIBA}

Além das características gerais atribuídas a uma cidade e destino inteligente, tais como a incorporação de tecnologias de informação e comunicação, o uso criativo, inovador e sustentável de serviços e produtos, a participação mais ativa dos cidadãos e o governo, entre outros, esta conta ainda com a questão da mobilidade inteligente, ou smart mobility, que se baseia na utilização de sistemas menos agressivos ao meio-ambiente e mais sustentáveis para a mobilidade urbana.

Uma das soluções relacionadas a transporte e mobilidade das cidades inteligentes é a implantação de planos de smart cycling e transporte integrado multimodal, já implantadas em cidades como Copenhagen, Paris e Londres, onde os impactos previstos são a redução de emissão de $\mathrm{CO}^{2}$ através de redução de congestionamento, vida saudável, aumento de transporte público e aprimoramento do transporte e competitividade (European Parliament, 2014, p. 85).

Outra solução proposta para o smart mobility deriva da Espanha através do compartilhamento de bicicletas chamado bike-sharing (ONSTI, 2015, p. 238), que reafirma a importância das bicicletas para um futuro mais saudável. 
A cidade "verde e inteligente" de Copenhagen, assim intitulada através do seu Plano Municipal Principal 2011, por exemplo, almeja que um terço dos trajetos deverão ser feitos por bicicletas (City of Copenhagen, 2012, p. 42). Ademais, através de seu Plano Climático CPH 2025, até o ano de 2025, 50\% dos trajetos dos seus cidadãos para escola ou trabalho na cidade devam ser realizados através da bicicleta como meio de transporte (Idem, ibidem, p. 45).

A implantação e incentivo à utilização de bicicletas como meio de transporte para os cidadãos e visitantes das cidades, em especial àquelas que buscam ser consideradas inteligentes é muito recorrente, sendo tema presente em diversos congressos, tais como o l Congreso Ciudades Inteligentes: movilidad inteligente e o II Congreso Ciudades Inteligentes: movilidad sostenible y conectada (Congreso Ciudades Inteligentes, 2016), ocorridos no ano passado e no corrente ano, na Espanha, e também faz parte de iniciativas brasileiras premiadas, tais como: aplicativo Bike Cidadão (esmartcity.es, 2015), aplicativo que busca melhorar a mobilidade urbana, segurança, respeito e educação entre pedestres e condutores de meios de transportes; campanha Ciclocidade - Bicicleta Faz Bem ao Comércio (Ciclocidade, 2015), que possuía o objetivo de sensibilizar comerciantes paulistas sobre a presença cada vez maior de ciclistas. Aliás, a cidade de Curitiba/PR irá receber menção honrosa no Prêmio Internacional de Transporte Sustentável 2017, promovido pelo Instituto de Políticas de Transporte e Desenvolvimento, pela abertura de dados do transporte público e o projetopiloto de aluguel de bicicletas elétricas no Parque Barigui (Menezes, 2016).

No que se refere a atividade ciclística aliado ao serviço turístico: "Um número crescente de turistas domésticos e estrangeiros optam por férias ativas, as quais resultam em aumento de demanda por programas relacionados ao ciclismo" (Central Europe, 2012, p. 15).

Ainda define como ciclismo turístico a combinação de diferentes tipos de ciclismo, que se difere basicamente pelo tipo de bicicleta utilizada (Idem, ibidem, p. 7), aliado a experimentação de belezas naturais, atrações culturais 
e especialidades etnológicas de certos lugares e regiões turísticas (Idem, ibidem, p. 6).

Claro é que, dentre as práticas de atividades de lazer e recreativas nos espaços urbano-turísticos das cidades, o uso da bicicleta é relevante. Vieira (2003) afirma que o cicloturismo não é uma competição, e sim uma modalidade sobre duas rodas voltada ao lazer, para praticar a agradável sensação de poder realizar viagens ou longos passeios com uma bicicleta.

O cicloturismo é um conceito novo que remete a ideia do lazer e da percepção do espaço urbano-turístico através das imagens e do visual captadas por cada indivíduo de diferentes formas. Portanto pode se dizer que o cicloturismo propicia no imaginário dos turistas diferentes sensações e representações visuais e que o cicloturista carrega consigo um carisma natural. Ele reflete de forma saudável o desejo de liberdade e aventura que está incutido em todo ser humano. Durante as viagens algumas pessoas impressionam-se, outras se identificam com o que está fazendo, e tentam de alguma forma se aproximar.

O cicloturismo transpõe às pessoas esse conhecimento imaginário de forma diferenciada, porque o uso da bicicleta traz consigo outras características. Segundo a Secretaria Nacional de Transporte e Mobilidade Urbana do Ministério das Cidades (CREA-ES, 2012), a bicicleta: promove a liberdade; faz sentir o vento no rosto; carrega sua bagagem; não polui; não congestiona a cidade; não necessita combustível; colabora com a sua saúde e a do planeta; possibilita estar próximo à natureza e, é silenciosa. O cicloturismo ainda é uma atividade relativamente recente e pouco difundida, que necessita de infraestrutura, planejamento urbano adequado, acessibilidade, segurança, e articulação com as políticas sociais e ambientais para sua realização (Vieira, 2003).

A Prefeitura de Curitiba, através de seus órgãos administrativos, tem desenvolvido e implantado diversos projetos de incentivo ao uso da bicicleta na cidade com o intuito específico de avançar nas discussões sobre ciclistas, 
pedestres e acessibilidade. O planejamento e introdução de paraciclos e bicicletários nos terminais de transporte coletivo, bem como a estruturação de vias cicloviárias de forma útil e eficiente, conectando aos poucos uma rede integrada de acesso à cidade são exemplos das ações tomadas. Inclusive o Instituto Municipal de Turismo também já incorporou o Cicloturismo como nova forma de atração para Curitiba lançando dois roteiros específicos para o turista visitar a cidade com o uso da bicicleta.

Müller (2004) destaca que Curitiba é considerada uma metrópole que tem em seu viés a questão urbana sob um enfoque humanista, onde a cidade é, prioritariamente, de quem nela vive. Nesse sentido, o mesmo autor aponta que desde a década de 1970, a cidade pode ser considerada pioneira na aplicação das questões da semiótica dentro do seu planejamento urbano, sendo que essa relação pode ser percebida, de maneira direta, mediante a análise do sistema do transporte público, dos programas ambientais, culturais e sociais implantados ao longo dos anos pelas ações de planejamento da cidade e, que consequentemente ganham significados próprios.

Quanto ao fluxo de turistas em Curitiba, com base nas pesquisas de demanda, em 2012 a cidade recebeu 3.714.184 turistas, ou seja, 2,59\% a mais do que em 2011, quando a estimativa de turistas de Curitiba ficou em 3.620.505 turistas. Nos anos seguintes, 2013 e 2014, Curitiba recebeu respectivamente, 3.916 .466 e 4.122 .764 visitantes (Brasil, 2014a).

A pesquisa de Horodyski, Manosso \& Gândara (2012) investigou a percepção da cidade pelos turistas e os seus hábitos de consumo. Os resultados demonstraram que as principais palavras associadas à Curitiba foram "beleza", "parques/natureza" e "limpeza" que indicam uma experiência mais contemplativa. As principais emoções foram "alegria" e "felicidade", seguidas de "tranquilidade" e "relaxamento", todas relacionadas a um sentimento positivo. Referente a experiência turística mais marcante, os turistas consideram principalmente a visita aos parques, que pode ser mais ativa, quando envolve a prática de atividades de lazer e 
recreativas nos parques, ou mais passiva, quando ocorre apenas uma visita para conhecer e contemplar o espaço. Este cenário evidencia os interesses do turista em visitar Curitiba e viver experiências de contemplação e entretenimento (Pazini, 2015).

O Turismo em Curitiba foi uma consequência das construções feitas por iniciativa do poder público para o bem-estar da população. A cidade de Curitiba continua se aperfeiçoando para garantir a seus moradores bem estar, mobilidade e preservação do patrimônio ambiental e cultural da cidade (Brasil, 2014b). Sabe-se que a existência dos parques e das áreas verdes contribui, de maneira direta, com a formação e a disseminação da imagem turística de Curitiba (Rabassa, 2012).

Para Rechia (2005), Fernandes, Gândara \& Souza (2011), Bonfim \& Bahl (2012) e Carvalho (2008) pode se creditar as denominações que Curitiba recebe de seus turistas à divulgação de aspectos relacionados ao seu planejamento, que se iniciou em 1970, onde se deixava transparecer que a cidade passava por uma "revolução" e que devia se tornar um modelo de planejamento e qualidade de vida para as demais cidades do país e do mundo.

Desde o início do planejamento da cidade, percebe-se a criação de parques urbanos: atualmente a cidade possui 26 parques, bosques e aproximadamente 82 milhões metros quadrados de áreas verdes preservadas. Os parques urbanos do destino foram pensados inicialmente como solução para problemas urbanos, mas acabaram por dinamizar a atividade turística na cidade, conformando, ao mesmo tempo, ambientes naturais protegidos e espaços da história e cultura da cidade. (Curitiba, 2015)

Conforme Manosso (2015), a relevância dos parques, praças e bosques de Curitiba para os turistas é corroborada em diversas pesquisas. Uma das pesquisas divulgadas pelo Instituto Municipal de Turismo em 2011, demostra que os maiores percentuais de visitantes nos atrativos turísticos de Curitiba 
estão nos Parques da cidade, com destaque para o Jardim Botânico, Parque das Pedreiras e Parque Tanguá.

Gândara (2003, p. 166) defende que o fato de Curitiba ser uma cidade planejada e o resultado deste planejamento ser a qualidade de vida da população local fez com que a imagem de qualidade ambiental tenha se transformado no principal atrativo turístico da cidade. Estas características do planejamento urbano de Curitiba são elementos que serviram para produzir importante renovação do sentimento de identidade da população local, e certamente, devem também ser utilizados como diferenciais dentro do marketing a ser desenvolvido. A possibilidade de considerar a qualidade ambiental urbana como um atrativo turístico faz da cidade um destino turístico privilegiado.

No que tange às iniciativas para o desenvolvimento do cicloturismo na cidade de Curitiba, a KuritBike, é uma empresa especializada em bike tours guiados e aluguel de bicicletas, que integra o nosso objeto de estudo. Através da infraestrutura da cidade existente, a empresa possibilita o aluguel de bicicletas e tours entre os pontos de interesse turístico natural e cultural, servindo também ao deslocamento de turistas (Curitiba, 2015). Vale ressaltar que Curitiba conta atualmente (setembro/2015) com uma malha cicloviária com cerca de 190 quilômetros incluindo as vias calmas, as ciclovias, as ciclofaixas, as ciclorrotas e os passeios compartilhados (Curitiba, 2015).

Pazini (2015) afirma que o cicloturismo adotado pela KuritBike, compreende o deslocamento de bicicleta com o proposito de lazer, no qual a ação pedalar faz parte integral da experiência turística, seja como meio de transporte para o destino, ou pela sua utilização no destino para realização de roteiros turísticos locais.

\section{PROCEDIMENTOS METODOLÓGICOS}

Este trabalho foi realizado a partir da análise de seu objetivo, portanto, pode ser considerada uma pesquisa de cunho exploratório. Michel (2009) e 
Gil (1991) caracterizam a pesquisa exploratória como sendo uma maneira de proporcionar uma maior familiaridade, isto é, conhecimento acerca do problema de pesquisa do tema a ser pesquisado, tornando-o mais explícito para a construção de hipóteses pesquisáveis de acordo com os objetivos do trabalho. Gil (1994, p. 45) destaca, assim, que "pode-se dizer que estas pesquisas têm como objetivo principal o aprimoramento de ideias ou a descoberta de intuições".

Dencker (1998, p. 58) cita que "a pesquisa exploratória procura aprimorar ideias ou descobrir intuições", sendo qualificada por possuir uma maior flexibilidade quanto ao seu planejamento, que, em geral, pode envolver "levantamento bibliográfico, entrevistas com pessoas experientes e análises de exemplos similares".

A pesquisa documental, por sua vez, difere-se da pesquisa bibliográfica por se tratar da análise de materiais que ainda não receberam "tratamento analítico" ou que até mesmo, podem ser reelaborados. Creswell (2007, p. 192) salienta que os documentos que podem ser empregados nessa técnica de pesquisa são os seguintes: "documento públicos, como atas e reuniões e jornais; documentos privados, como registros, diários e cartas e discussões viaemail".

É toda informação de forma oral, escrita ou visualizada. A pesquisa documental consiste na coleta, classificação, seleção difusa e na utilização de toda espécie de informações, compreendendo também as técnicas e métodos que facilitam a sua busca e a sua identificação (Fachin, 2006, p. 146).

A pesquisa bibliográfica, de acordo com Cervo \& Bervian (1983, p. 55) "procura explicar um problema a partir de referências teóricas publicadas em documentos". Sua principal característica é buscar conhecer, bem como, analisar as contribuições científicas oriundas de pesquisas passadas sobre determinada temática, assunto ou problema.

Hack Neto (2015) descreve que desde os tempos mais remotos o homem e depois a sociedade se expressam no tocante a seus espaços vividos ou 
percorridos por meio de representações. Paredes de caverna, blocos de rocha, pinturas rupestres, pergaminhos, papel e meio digital demonstram uma clara evolução do homem em relação à representação e, portanto, à comunicação.

A técnica de netnografia, considerada recente dentro do contexto das pesquisas acadêmicas, é trabalhada como uma fonte de informação para que se possa determinar qual a imagem e o posicionamento das empresas no contexto do ciberespaço (Clemente Ricolfe \& Escribá-Pérez, 2014). Kozinets (1998) e Pereira (2005) definem a netnografia como uma adaptação dos métodos qualitativos empregados nas pesquisas relacionadas ao consumo, a antropologia cultural e estudos culturais, tendo como objetivo proporcionar um estudo contextualizado do comportamento do consumidor dentro de comunidades virtuais e de produtos da cibercultura.

Kozinets (2002) e Turpo (2008) destacam que netnografia é composta por duas fases: recolha de dados e interpretação humana. Deste modo, a primeira fase deste trabalho diz respeito à busca do material dentro do ciberespaço. Neste caso, optamos pelas fotografias dos cicloturistas, clientes da empesa KuritBike - primeira empresa de cicloturismo do Brasil, criada há seis anos, que possui pouco mais de 100 bicicletas em sua frota, ofertando oito diferentes roteiros na cidade de Curitiba - postadas no site TripAdvisor. Nesse sentido, vale ressalvar que a internet desponta como uma fonte capital da midiatização do turismo na atualidade (Richards, 2009; Middleton, 2002). Não por acaso, tem sido adotada com bastante pujança como canal de promoção e divulgação turística, bem como de comunicação entre o trade turístico e instâncias de governança com o turista (Buhalis \& Law, 2008). Turpo (2008), aliás, ressalva o potencial da internet para a contextualização de tendências de mercado ao possibilitar o acesso a informações em tempo real acerca do consumo de produtos e serviços.

Cabe, portanto, situar a internet no contexto da cibercultura. Para Lemos \& Levy (2010, p. 22), esta é "uma forma sociocultural que modifica 
hábitos sociais, práticas de consumo cultural, ritmos de produção e distribuição da informação, criando novas relações no trabalho e no lazer, novas formas de sociabilidade e de comunicação social". E o primeiro princípio da cibercultura, segundo os autores, é a liberação da palavra ou liberação da emissão, cuja ideia baseia-se na configuração de novas formas de conversação e de circulação da informação na contemporaneidade. Tal processo possibilita a qualquer pessoa o acesso à produção de conteúdo, sem dispender de vultosos recursos financeiros ou depender de algum tipo de concessão.

Entre os sistemas e ferramentas de comunicação gerados a partir da liberação da palavra estão os sites com conteúdo colaborativos, como TripAdvisor. Trata-se do maior portal online de viagens do mundo, assim autointitulado, cujas características abrangem: ajuda aos viajantes a descobrir o potencial de cada viagem por meio de postagens colaborativas, tanto escritas como fotográficas, e traz dicas de viajantes, além de recursos de planejamento, entre outros (Tripadvisor, 2016). O TripAdvisor é considerado por Lu \& Stepchenkova (2015, p. 120), como uma grande plataforma de mídia social que contêm grandes volumes de conteúdo gerado por usuário, o que é adequado para investigação no que diz respeito ao turismo, hospitalidade e suas aplicações.

Para Thomaz, Biz \& Gândara (2013, p. 103), "nos últimos anos, o surgimento de novos meios e redes sociais facilitaram e contribuíram a produção de conteúdo e compartilhamento de informação entre as pessoas". Bosangit, Hibbert \& McCabe (2015), que analisaram a transformação das experiências do turismo em experiências pessoalmente significativas a partir da análise de dezenove blogs de viagem britânicos, destacam a sua relevância para a gestão e marketing turístico. Os autores defendem que tais websites fornecem dados relevantes acerca do comportamento dos turistas, da imagem e da avaliação dos destinos. Assim também são os sites colaborativos destinados a informações sobre viagens. 
Na segunda fase considerada a de interpretação manual, foram analisadas as fotografias e classificadas de acordo com as variáveis e conceitos da morfologia, da paisagem e da imagem do espaço urbano e das representações urbano-turísticas, organizadas por Manosso (2015), abordadas por Lynch (1982); Boullón (2002); Lamas (2004) e Cullen (1983), com o intuito de verificar qual é a representação urbano-turística que o cicloturista possui da cidade de Curitiba.

Para análise das fotos postadas no site TripAdvisor, foram selecionadas 162 de todas as 196 fotos disponibilizadas até o mês de janeiro de 2015. As 34 fotos eliminadas estavam desfocadas ou eram selfies, que impossibilitavam a identificação do local onde estavam os cicloturistas.

\section{RESULTADOS E ANÁLISES}

A Tabela 2 foi adaptada de Manosso (2015) pelos autores a fim de possibilitar a análise proposta neste trabalho. Refere-se às representações urbano-turísticas e as categorias de análise referentes ao espaço urbano que foram detectadas nas fotografias postadas por cicloturistas no TripAdvisor sobre Curitiba.

Tabela 2: categorias de análise do espaço urbano-turístico

(continua)

\begin{tabular}{|c|c|c|c|}
\hline $\begin{array}{l}\text { Representações } \\
\text { Urbano-Turísticas }\end{array}$ & Quantidade & Categorias & $\begin{array}{l}\text { Número de fotos } \\
\text { identificadas }\end{array}$ \\
\hline \multirow{3}{*}{ Histórico-Cultural } & \multirow{3}{*}{79} & Marcos & 17 \\
\hline & & Monumentos & 21 \\
\hline & & Fachadas & 41 \\
\hline \multirow{4}{*}{ Natureza } & \multirow{4}{*}{36} & Parques & 25 \\
\hline & & Passeios Públicos e Jardins & 7 \\
\hline & & Praças & 1 \\
\hline & & Ruas Arborizadas & 3 \\
\hline
\end{tabular}

(conclusão)

\begin{tabular}{|lccc|}
\hline & & Vias (Caminhos) = Estradas, & 19 \\
Uuas, traçados, calçadas. & \\
Urbana & 32 & Sinalização Urbana e & 8 \\
\cline { 2 - 4 } & & Turística & 5 \\
\hline Entretenimento & 15 & Gobiliário Urbano & 15 \\
\hline
\end{tabular}


TOTAL 162 162

Fonte: Manosso (2015) com base em Lynch (1982); Boullón (2002); Lamas (2004) e Cullen (1983) adaptada pelos autores.

As representações urbano-turísticas e histórico-culturais divulgadas no site do TripAdvisor, teve o maior número de fotos (79 postagens). Tal constatação demonstra o perfil do cicloturista e o seu olhar para as questões da cidade. Vale ressaltar que os passeios Bike Tour Fotográfico Noturno, Bike Tour Opera de Arame e Museu Oscar Niemeyer e o Arte Bike Tour, ofertados pela Kuritibike, proporcionam ao cicloturista conhecer, em especial, aspectos culturais de Curitiba.

Imagens de obras de arte e muros grafitados (Figura 1), sendo categorizados como fachadas no quadro apresentado anteriormente, tiveram o maior número de fotografias dentre as representações históricoculturais, bem como o Museu Oscar Niemeyer (Figura 2), Paço da Liberdade e a Universidade Federal do Paraná -UFPR (Figura 3). Curitiba ainda é um destino que busca o desenvolvimento do segmento turístico cultural e, desta forma, o cicloturismo pode ser um fomentador para auxiliar na formação da identidade cultural da cidade.

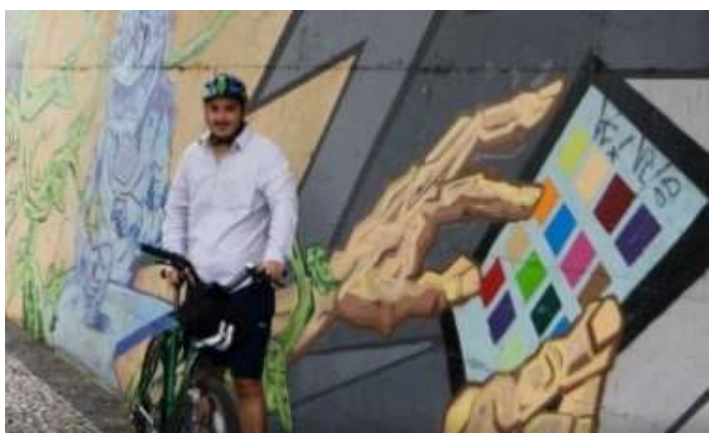

Figura 1: Arte em Grafite.

Fonte: TripAdvisor, 2013.

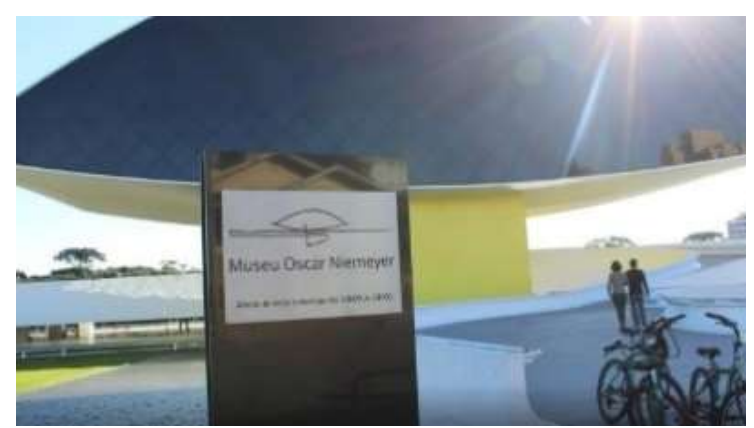

Figura 2: Museu Oscar Niemeyer. Fonte: TripAdvisor, 2013.

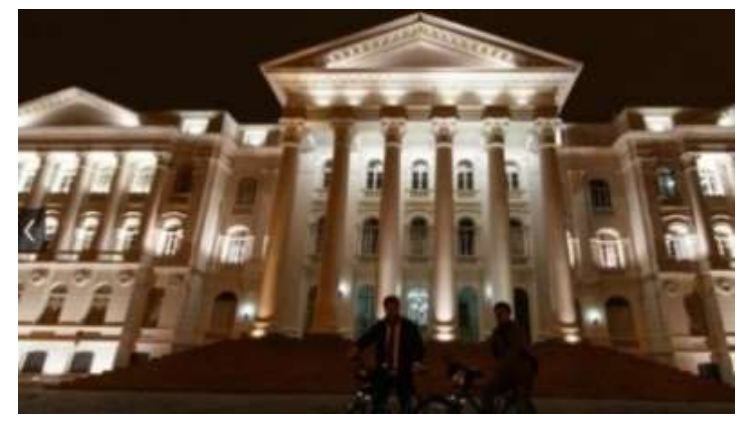


Figura 3: UFPR

Fonte: TripAdvisor, 2015.

Quanto às fotografias da categoria Natureza, nas 36 analisadas, evidenciam-se os parques, que são os principais atrativos turísticos da cidade. Uma característica diferenciada destes atrativos naturais em Curitiba é o aproveitamento de antigos espaços naturais antes utilizados para exploração econômica e que após criação dos parques e bosques foram aproveitados para compor a paisagem natural, como o caso das antigas pedreiras. Atualmente, Curitiba possui 26 parques que foram pensados como soluções para problemas urbanos e acabaram por dinamizar a atividade turística na cidade conformando, ao mesmo tempo, ambientes naturais protegidos e espaços da história e cultura da cidade (Curitiba, 2015).

Cada parque possui características diferentes e alguns, possuem atrativos relacionados aos aspectos ambientais e outros aos aspectos culturais da cidade. A formação histórica e cultural de Curitiba é marcada pela presença de diversas etnias que influenciam e marcam a sua paisagem urbana (Horodyski, 2014, p. 149).

Sabe-se que a existência de parques contribui, de maneira direta, com a formação e a disseminação da imagem turística de Curitiba (Rabassa, 2012). E nas fotos abaixo registradas pelos cicloturistas percebe-se o encantamento pelos parques, ruas arborizadas, praças e jardins de Curitiba, como o Parque Tanguá (Figura 4) e o Jardim Botânico (Figura 5). Com o significativo número de fotos da categoria Natureza e sendo Curitiba uma cidade conhecida por seus parques e praças, o número expressivo de fotos publicadas corrobora que estes são simbólicos para a imagem da cidade. Vale ressaltar que dos oito passeios ofertados aos cicloturistas da KuritBike, quatro deles levam aos parques da cidade. 


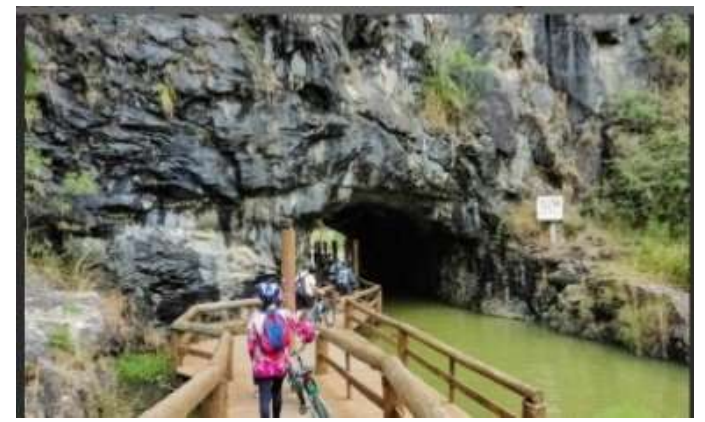

Figura 4: Parque Tanguá.

Fonte: TripAdvisor, 2013.

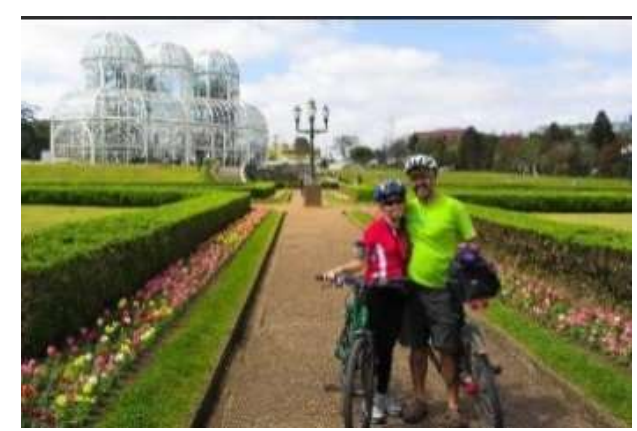

Figura 5: Jardim Botânico.

Fonte: TripAdvisor, 2012

Dentre as 32 fotos das representações urbano-turísticas da categoria Urbana, é possível perceber que as vias, bem como a sinalização urbana e o mobiliário urbano são admirados pelos cicloturistas. Vale ressaltar que Curitiba é uma das cidades brasileiras que fortemente incorporou os efeitos das ações planejadas do seu espaço urbano, sendo esta, uma peculiaridade do seu planejamento urbano, que resultou numa configuração urbana própria e em equipamentos públicos exaltados e admirados mundialmente. Tal fato não se atém à existência física dos espaços urbanos, mas também a formação deliberada de uma imagem de cidade planejada. Segundo Menezes (1996, p. 16), "experiências urbanas inovadoras e criativas, que até bem pouco tempo atrás ficavam circunscritas a seus territórios, hoje são reconhecidas e divulgadas em todo o mundo".

Uma pesquisa realizada pela Universidade Federal do Paraná, em parceria com o Instituto Municipal de Turismo, no período da Copa do Mundo FIFA (2014), comprovou essa imagem acerca da visão do turista em relação à cidade de Curitiba, que demonstra que 25,4\% dos turistas entrevistados apontam a imagem de Cidade Planejada e Organizada, e 21,7\% como Cidade com Qualidade de Vida, o que evidencia a projeção de cidade planejada e com referências e destaques ao seu planejamento urbano.

O turismo urbano ainda se apropria da paisagem das cidades para desenvolver sobre ela leituras criativas. Nos roteiros, podem ser observadas as facilidades de fluxo das pessoas e dos veículos, a agradabilidade estética, a paisagem construída, os serviços urbanos, os equipamentos de apoio ao 
turismo e o mobiliário urbano (placas de sinalização, paradas de ônibus, postes, brinquedos das praças, dentre outros) (Boullón, 2002; Castrogiovanni, 2000). As figuras 6 e 7 demonstram que estes componentes compõem a representação urbana nas fotos postadas por cicloturistas no TripAdvisor.

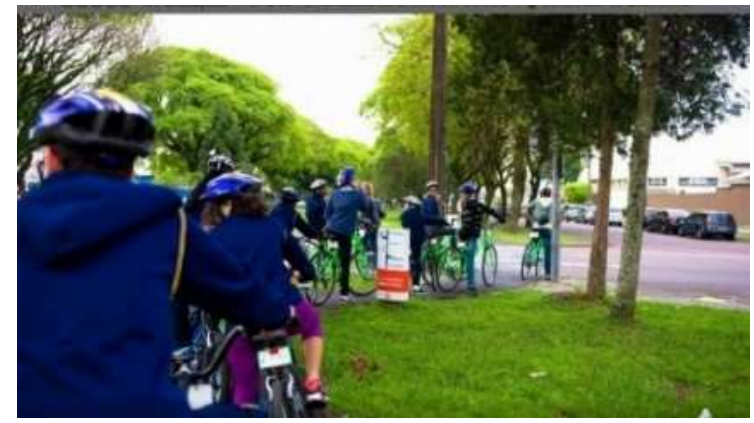

Figura 6: Ciclovia e placa de sinalização. Fonte: TripAdvisor, 2014.

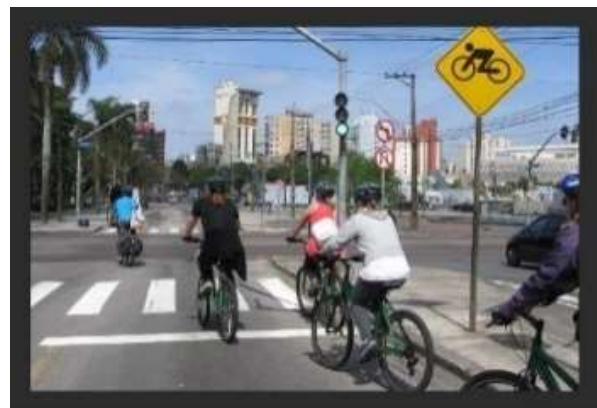

Figura 7: Canaleta do ônibus com ciclovia. Fonte: TripAdvisor, 2015.

Para as representações urbano-turísticas da categoria Entretenimento, um número menor de fotos foi postado no site TripAdvisor (15 imagens), sendo todas relacionadas a gastronomia. Todavia, deve-se ressaltar a dificuldade de compatibilizar atividades de entretenimento, sobretudo de mais longa duração, como teatro, cinema, shows e eventos, com o cicloturismo. Ademais, Curitiba apresenta, atualmente, diversos roteiros gastronômicos, o que já aparece nas pesquisas de demanda de Curitiba, nas motivações e atividades pretendidas pelos turistas, com 3,2\% do público para a gastronomia (Brasil, 2014a). Mesmo que seja um percentual ainda pouco expressivo, em pesquisas anteriores sequer aparecia. A própria empresa Kuritbike oferece roteiros relacionados ao entretenimento gastronômico, como o Bike Bar e o Bike Coffee, o que também justifica a ocorrência apenas desta representação urbano-turística na categora Entretenimento, como demonstrado nas figuras 8 e 9 .
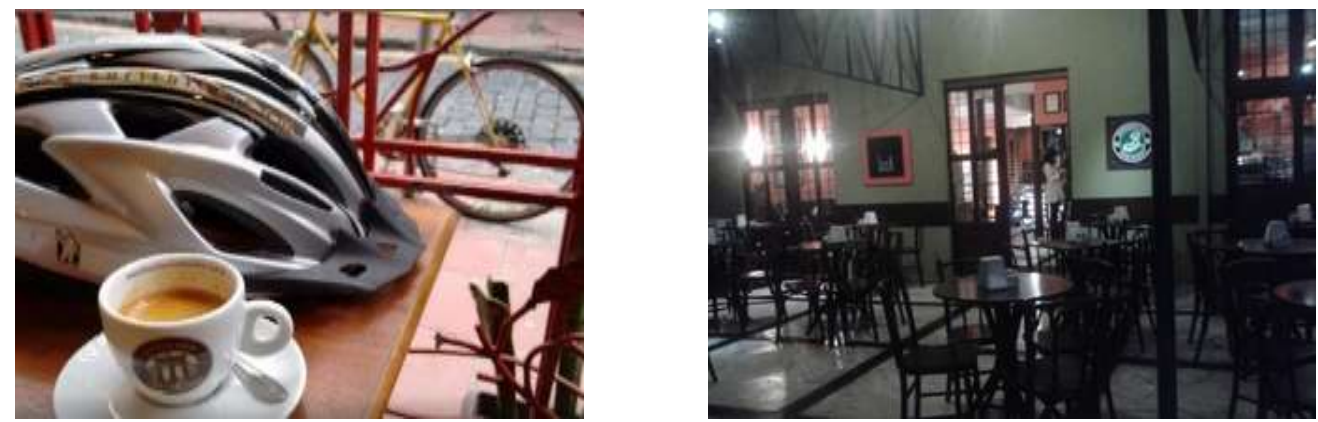
Figura 8: Degustação de café.

Fonte: TripAdvisor, 2015.
Figura 9: Cafeteria Lucca.

Fonte: TripAdvisor, 2015.

De modo geral, observou-se, portanto, que a representação urbanoturística de Curitiba nas fotos analisadas está mais centrada nos aspectos histórico-culturais. Entretanto, os resultados mostram que também abarca outras duas dimensões bastante enfatizadas no planejamento urbano da cidade, compreendidas nas categorias Urbana e Natureza. Já o entretenimento, especialmente o gastronômico, surge de modo emergente, conforme mencionado anteriormente. Cabe ressaltar que a veiculação destas imagens pelos cicloturistas em um site de conteúdo colaborativo, usufruindo dos atrativos turísticos da cidade, tem potencial de referendar e recomendar ao turista em potencial as experiências que este poderá vivenciar no destino turístico Curitiba.

\section{CONSIDERAÇÕES FINAIS}

Com história de inovação e investindo em sustentabilidade e eficiência, Curitiba mantém-se comprometida com o conceito de cidade que respeita seus aspectos ambientais, constantemente procurando maneiras de fazer os seus sistemas mais competentes, mostrando-se como modelo para cidades ao redor do mundo.

A análise da representação urbano turística do destino Curitiba através das fotografias postadas pelos cicloturistas no site do TripAdvisor ${ }^{\circledR}$ e a percepção do olhar que o cicloturista possui para a cidade, objetivo proposto neste trabalho, possibilitou verificar que a experiência turística vivenciada por este tipo de turista teve maior enfoque nas questões histórico-culturais, o que diferencia o cicloturista do turista tradicional.

As pesquisas sobre turismo na cidade de Curitiba retratam maior enfoque para os parques e praças, para as questões ambientais e de qualidade de vida, contudo, no caso dos cicloturistas que optaram por roteiros turísticos da KuritBike, foi possível perceber a apreciação dos marcos da cidade como o Museu Oscar Niemeyer, o Paço da Liberdade, a Catedral Metropolitana de 
Curitiba e a Universidade Federal do Paraná, bem como os monumentos e as fachadas visitadas pelos cicloturistas.

Cabe ressaltar que o cicloturista fotografou e postou muitas fachadas com as obras e os grafites da cidade, o que reafirma que o espaço urbano não é construído para uma pessoa, mas para várias, que apresentam diferenças de temperamento, formação, ocupação profissional, origem étnica, diversidade social e, portanto, interesses. Assim, a cidade é uma representação da condição humana, sendo que essa representação se manifesta por meio da arquitetura em si e da ordenação de seus elementos.

\section{REFERÊNCIAS}

Associacion Española de Normalizacion y Certificacion - AENOR. (2016). Gestionar el modelo turístico del siglo XXI. Disponível em: <www.aenor.es/revista/314/destinos-turisticos-inteligentes.html>. Acesso em: 30 out. 2016.

Ávila Muñoz, A. L. (2013). Creating a smart destination. Disponível em: <www.morocco-forum.com/downloads/presentations/Antonio-lopezde-Avila-Munoz-Creating-a-Smart-Destination.pdf>. Acesso em: 30 out. 2016.

Bettencourt, L. C. F. A. (2010). A cidade e sua morfologia urbana. Malha Urbana. 10, 25-53.

Bonfim, I. O. B. \& Bahl, M. (2012). A cidade de Curitiba (PR) - Brasil: $\bigcirc$ turismo e suas imagens simbólicas. Revista Cultura e Turismo. 6(4), 72-85.

Bosangit, C., Hibbert, S. \& McCabe, S. (2015). "If I was going to die I should at least be having fun": Travel blogs, meaning and tourist experience. Annals of Tourism Research. 55, pp. 1-14.

Boullón, R. C. (2002). Planejamento do espaço turístico. Bauru: EDUSC.

Brasil. (2014b). Planejamento urbano é destaque em Curitiba. Disponível em: <http://www.turismo.gov.br/\%C3\%BAltimas-not\%C3\%ADcias/4088planejamento-urbano-e-destaque-em-curitiba.html>. Acesso em: 30 out. 2016.

Brasil. (2014a). Plano de Desenvolvimento Integrado do Turismo Sustentável PDITS. Curitiba. Disponível em: 
<www.turismo.gov.br/sites/default/turismo/DPROD/PDITS/PARANA/PDI TS_DO_MUNICIPIO_DE_CURITIBA.pdf>. Acesso em: 30 out. 2016.

Buhalis, D. \& Law, R. (2008). Progress in information technology and tourism management: 20 years on and 10 years after the Internet - The state of eTourism research. Tourism Management, 29, pp. 609-623.

Caragliu, A.; Del Bo, C. \& Nijkamp, P. (2009). Smart cities in Europe. 3rd Central European Conference in Regional Science - CERS. 45-59.

Carvalho, A. S. (2008). Curitiba: Imagem do Planejamento ou Planejamento da Imagem? Monografia (Curso de História). Setor de Ciências Humanas, Letras e Artes, Curitiba: Universidade Federal do Paraná.

Castrogiovanni, A. C. (Org). (2000). Ensino de geografia: Práticas e textualizações no cotidiano. Porto Alegre: Mediação.

Center on Governance (2003). SmartCapital Evaluation Guidelines Report:

Performance Measurement and Assessment of Smart Capital. Ottawa, Canada: University of Ottawa.

Central Europe (2012). How to develop cycle tourism? Eslovênia. Disponível em: <http://bicy.it/docs/35/How_to_develop_cycle_tourism_ang.pdf>. Acesso em: 30 out. 2016.

Cervo, A. L. \& Bervian, P. A. (1983). Metodologia Científica, São Paulo: McGraw Hill do Brasil.

Ciclocidade. (2015). Campanha da Ciclocidade ganha prêmio da Transporte Ativo. Disponível em:

<www.ciclocidade.org.br/noticias/822-campanha-da-ciclocidadeganha-premio-da-transporte-ativo>. Acesso em: 30 out. 2016.

City of Copenhagen (2012). CPH 2025 - Climate Plan. Copenhagen: Technical and Environmental Administration.

Clemente Ricolfe, J. S. \& Escribá Pérez, C. (2014). Aplicando netnografía a la obtención del mapa de posicionamiento para empresas de distribución alimentaria. Cuadernos de Gestión. (14)1. 57-74.

Comissão Europeia. (2000). Para um turismo urbano de qualidade - Gestão integrada da qualidade (GIQ) dos destinos turísticos urbanos. Resumo. Direção-Geral da Empresa, Unidade Turismo. Luxemburgo: Serviço das Publicações Oficiais das Comunidades Europeias, 2000. 14p. ISBN 92828-7843-0

Congreso Ciudades Inteligentes. (2016). III Congreso Ciudades Inteligentes. 
Disponível em: <http://www.congreso-ciudades-inteligentes.es/>. Acesso em: 30 out. 2016.

Conselho Regional de Engenharia e Agronomia do Estado do Espirito Santo CREA/ES. Curiosidades sobre o uso da bicicleta no Brasil e no mundo. Disponível em:

<www.creaes.org.br/creaes/Portals/0/Documentos/cartilhas/folder_ci clovias.pdf>. Acesso em: 30 out. 2016.

Creswell, J. W. (2007). Projeto de Pesquisa: Método qualitativo, quantitativo e misto. Porto Alegre: Artmed.

Cullen, G. (1983). Paisagem Urbana. Lisboa: Edições. 70.

Curitiba (2015). Mais Bici. Mapas de estruturas, rotas cicloviárias e cicloturísticas. Disponível em:

<http://www.curitiba.pr.gov.br/conteudo/mais-bici-mapas-com-rotasde-ciclofaixas-e-ciclorrotas/2216>. Acesso em: 30 out. 2016.

Curitiba (2015). Prefeitura Municipal de Curitiba. Disponível em: <www.curitiba.pr.gov.br>. Acesso em: 30 out. 2016.

Custódio, R. B. (2006). A influência das intervenções urbanísticas na atividade turística da cidade de Curitiba. Dissertação de Mestrado (Mestre em Gestão Urbana), Programa de Pós-Graduação em Gestão Urbana, Curitiba: Pontifícia Universidade Católica do Paraná.

Dencker, A. F. M. (1998). Pesquisa em Turismo: planejamento métodos e técnicas. São Paulo: Futura.

ESMARTCITY.ES. (2015). Ganadores de la Gran Final de Smart City App Hack en la SCEWC. Disponível em: <wWw.esmartcity.es/noticias/ganadoresde-la-gran-final-de-smart-city-app-hack-en-la-scewc>. Acesso em: 30 out. 2016.

European Parliament. (2014). Mapping Smart Cities in the EU. Policy Department Economic and Scientific Policy A. Disponível em: < www.europarl.europa.eu/RegData/etudes/etudes/join/2014/507480/I POL-ITRE_ET(2014)507480_EN.pdf>. Acesso em: 30 out. 2016.

Fachin, O. (2006). Fundamentos da Metodologia. 5ed. São Paulo: Saraiva.

Fernandes, D. L.; Gândara, J. M. G. \& Souza, T. A. (2011). A influência do planejamento urbano na percepção de visitantes e visitados e a formação da imagem de Curitiba. Balneário Camburiú: Seminário da Associação Nacional de Pesquisa em Turismo, Anais. 
Frey, K. (2000). Políticas públicas: um debate conceitual e reflexões referentes à prática da análise de políticas públicas no Brasil. Planejamento e Políticas Públicas. Brasília: IPEA. 21, p. 21 1-259.

Gândara, J. M. G. (2003). Ações comunicativas do destino turístico Curitiba. In: Rejowski, M. \& Costa, B. K. (org.). Turismo contemporâneo: desenvolvimento, estratégia e gestão. São Paulo: Atlas.

Gil, A. C. (1991). Como elaborar projetos de pesquisa. 3ed. São Paulo: Atlas.

Hack Neto, E. (2015). Percepções Turísticas: Foz do Iguaçu, Terra das Cataratas entre o real e o imaginário. Tese (Doutorado em Geografia), Curitiba: Universidade Federal do Paraná.

Horodyski, G. S. (2014). O Consumo Na Experiência Turística: O Caso Dos Souvenirs No Destino Curitiba - PR. Tese (Doutorado em Geografia). Curitiba: Universidade Federal do Paraná.

Horodyski, G. S.; Manosso, F. C. \& Gândara, J. M. G. (2012). O consumo de souvenirs e a experiência turística em Curitiba (PR). Caderno Virtual de Turismo. 12(3), p. 323-342.

Ivars Baidal, J. A.; Solsona Monzonís, F. J. \& Giner Sánchez, D. (2016). Gestión turística y tecnologías de la información y la comunicación (TIC): El nuevo enfoque de los destinos inteligentes. Documents d'Anàlisi Geogràfica. 62(2), p. 327-346.

Kozinets, R.V. (1998). On Netnography: Initial Reflections on Consumer Research Investigations of Cyberculture. NA - Advances in Consumer Research. (25) p. 366-371.

Kozinets, R.V. (2002). The field behind the screen: using netnography for marketing research in online communities. Journal of Marketing Research (39) p. 61-72.

Lamas, J. M. R. G. (2004). Morfologia Urbana e desenho da cidade. Lisboa: Fundação Calouste Gulbekian.

Lefebvre, H. (1999). A revolução urbana. Belo Horizonte: Universidade Federal de Minas Gerais.

Lefebvre, H. (2008). Espaço e Política. Belo Horizonte: Universidade Federal de Minas Gerais.

Leite, F. C. L. (2009). A morfologia urbana de Brasília como um fator influente 
na construção da imagem da cidade como um destino turístico. Dissertação de Mestrado (Mestre em Turismo e Hotelaria). Programa de Mestrado Stricto Sensu em Turismo e Hotelaria, Balneário Camburiú: Universidade do Vale do Itajaí.

Lemos, A. \& Lévy, P. (2010). O futuro da Internet: em direção a uma ciberdemocracia planetária. São Paulo: Paulus.

Lopes, S. A. (2010). Regeneração dos espaços exteriores urbanos: Proposta de Intervenção no bairro Godinha. Dissertação de Mestrado (Mestre em Arquitetura), Departamento de Engenharia Civil e Arquitetura. Covilhã: Universidade da Beira Interior.

Lu, W. \& Stepchenkova, S. (2015). User-generated content as a research mode in tourism and hospitality applications: Topics, methods, and software. Journal of Hospitality Marketing and Management. 24(2). p. 119-154. doi: 10.1080/19368623.2014.907758

Luque Gil, A. M.; Zayas Fernández, B. \& Caro Herrero, J. L. (2015). Los Destinos Turísticos Inteligentes en el marco de la Inteligencia Territorial: conflictos y oportunidades. Investigaciones turísticas. Disponível em: <www.investigacionesturisticas.es/iuit/article/view/206>. Acesso em: 30 out. 2016. doi: http://dx.doi.org/10.14198/INTURI2015.10.01

Lynch, K. (1997). A imagem da cidade. São Paulo: Martins Fontes.

Manosso, F. C. (2015). O Espaço Urbano-Turístico de Curitiba nas Fotografias On-Line: Uma análise na Rede Social Instagram. Dissertação de Mestrado, Departamento de Geografia. Curitiba: Universidade Federal do Paraná.

Menezes, C. L. (1996). Desenvolvimento urbano e meio ambiente: a experiência de Curitiba. Campinas: Papirus.

Menezes, F. Z. (2016). Curitiba recebe menção honrosa em prêmio de transporte sustentável. Gazeta do Povo. Disponível em: $<w w w . g a z e t a d o p o v o . c o m . b r / v i d a-e-c i d a d a n i a / f u t u r o-d a s-$ cidades/curitiba-recebe-mencao-honrosa-em-premio-de-transportesustentavel-exmjnxsk4||4uqbtip8jdd8oł>. Acesso em: 30 out. 2016.

Michel, M. E. (2009). Metodologia e Pesquisa Científica em Ciências Sociais: Um guia prático para acompanhamento da disciplina e elaboração de trabalhos monográficos. São Paulo: Atlas.

Middleton, V. T. (2002). Marketing de turismo: teoria e prática. Rio de Janeiro: Campus. 
Müller, J. (2004). Elementos semióticos no planejamento urbano: o caso de Curitiba. Dissertação (Mestrado em Geografia) - Setor de Ciências da Terra, Curitiba: Universidade Federal do Paraná.

ONSTI. (2015). Estudio y Guía metodológica sobre Ciudades Inteligentes. Disponível em: < http://www.ontsi.red.es/ontsi/es/estudiosinformes/estudio-y-gu\%C3\%AD-metodol\%C3\%B3gica-sobre-ciudadesinteligentes>. Acesso em: 30 out. 2016.

Pazini, R. (2015). Os produtos turísticos de Curitiba desde a perspectiva dos gestores das agências de turismo receptivo. Dissertação de Mestrado, Departamento de Turismo, Curitiba: Universidade Federal do Paraná.

Pereira, C. S. (2005). Imagine Yourself Set Down... In Front Of Your PC: A Etnografia e o Desafio Metodológico Da Netnografia. Revista de Antropología. (6). p. 1-21.

Rabassa, N.F. (2012). La Construcción de la Imagen de un Destino Turístico. In: ANTON, S.C. (editor) Lecciones sobre Turismo - el reto de reinventar los destinos. Espanha: Planeta.

Rechia, S. (2005). Espaço e planejamento urbano na sociedade contemporânea: políticas públicas e a busca por uma marca identitária na cidade de Curitiba. Revista Movimento. Porto Alegre. $11(3), 49-66$.

Richards, G. (2009). Turismo cultural: padrões e implicações. In: Camargo, P. \& Cruz, G. Turismo cultural: estratégias, sustentabilidade e tendências (pp.25-48). Ilhéus: Editus.

Rodrigues, A. B. (2002). Turismo, modernidade e globalização. São Paulo: Hucitec.

Santos, M. (1988). Metamorfose do espaço habitado. São Paulo: Hucitec.

Tripadvisor. (2016). Sobre o TripAdvisor. Disponível em:

$<$ www.tripadvisor.com.br/PressCenter-c6About_Us.html>. Acesso em: 30 out. 2016.

Thomaz, G. M.; Biz, A. A. \& Gândara, J. M. G. (2013). Innovación en la promoción en medios y redes sociales - Un estudio comparativo entre destinos turísticos. Estudios y Perspectivas en Turismo. 22, 102-1 19.

Turpo, O. (2008). La netnografía: método de investigación en Internet. Educar, 42, p. 81-93.

Tyler, D.; Guerrier, Y. \& Robertson, M. (org.). (2001). Gestão de Turismo 
Municipal. São Paulo: Futurama.

Vera Rebollo, J. F. \& Ivars Baidal, J. A. (2004) Indicadores de sostenibilidad para Destinos Maduros: Balance y propuestas de aplicación. Organización Mundial de Turismo "Creando Estructuras para la Investigación y la Educación en Política Turística y Gestión de Destinos". Disponível em: <http://rua.ua.es/dspace/handle/10045/20481>. Acesso em: 30 out. 2016.

Vieira, W. (2003). Cicloturismo. Revista Turismo. abr. 2003. Disponível em: <http://www.revistaturismo.com.br/Ecoturismo/cicloturismo.html>. Acesso em: 30 out. 2016.

Xiang, Z.; Tussyadiah, I. \& Buhalis, D. (2015). Smart destinations: Foundations, analytics, and applications. Journal of Destination Marketing \& Management. 4, 143-144. 